\title{
Impact of 'Modeling' of Teaching by Competency-based Approach on the Development of Professionalization Skills of Future Moroccan Teachers
}

\author{
Iman Elkababi ${ }^{1}$, Chaibia Srour ${ }^{1}$, Azzeddine Atibi ${ }^{2, *}$, Khadija Elkababi $^{2}$, Mohamed Radid ${ }^{1}$, \\ Souad Tayane ${ }^{3}$ \\ ${ }^{1}$ Laboratory of Physical Chemistry of Materials LCPM, Faculty of Sciences Ben M’sik, Hassan II University, Casablanca-Morocco \\ ${ }^{2}$ Regional Center for the Professions of Education and Training, Casablanca-Settat (CRMEF), Morocco \\ ${ }^{3}$ The Higher National School of Arts and Crafts of Casablanca, Hassan II University of Casablanca- Morocco
}

Received September 6, 2020; Revised October 21, 2020; Accepted November 11, 2020

\section{Cite This Paper in the following Citation Styles}

(a): [1] Iman Elkababi, Chaibia Srour, Azzeddine Atibi, Khadija Elkababi, Mohamed Radid, Souad Tayane, "Impact of 'Modeling' of Teaching by Competency-based Approach on the Development of Professionalization Skills of Future Moroccan Teachers," Universal Journal of Educational Research, Vol. 8, No. 12, pp. 6978 - 6987, 2020. DOI: 10.13189/ujer.2020.081265.

(b): Iman Elkababi, Chaibia Srour, Azzeddine Atibi, Khadija Elkababi, Mohamed Radid, Souad Tayane (2020). Impact of 'Modeling' of Teaching by Competency-based Approach on the Development of Professionalization Skills of Future Moroccan Teachers. Universal Journal of Educational Research, 8(12), 6978 - 6987. DOI: 10.13189/ujer.2020.081265.

Copyright $\subseteq 2020$ by authors, all rights reserved. Authors agree that this article remains permanently open access under the terms of the Creative Commons Attribution License 4.0 International License

\begin{abstract}
Despite the fact that teaching managers are fully aware of the components of the standard framework regarding the teaching profession, their professional practice does not reflect the integrity of the content of these texts; this encourages them to improve the quality of teaching through the use of the "competency-based approach" as a teaching method at schools and at teacher training centers (CRMEFs). In the current context of improving the quality of teaching and its proper viability, this study proposes a paradigm of the method, which respects the agreed upon pedagogical guidelines and that could guarantee effective teaching. It also suggests the exploration of the relationship between the "competency-based approach" and the development of communication skills, autonomy and self-confidence among teacher trainees. A modeling of the "competency-based approach" (CBA) teaching method has been carried out and tested with trainee teachers in physical sciences in secondary education to ensure its feasibility and effectiveness. Through this study, we proved that the implementation of this modeling contributed to the improvement of professionalization skills among new teachers.
\end{abstract}

Keywords Modeling of the "Competency-based Approach" (CBA), Experimentation, Feasibility and
Efficiency, Skills Development, Teacher-Trainees

\section{Introduction}

The competency-based approach has become established in the world of education, first in the United States, Australia and then in Europe. The United Kingdom, Switzerland and Belgium were among the first countries which have reconsidered their education systems according to this approach. In this context, a large number of education systems are engaged in reforms that place the competency-based approach (CBA) at the heart of the curricula: curriculum designers are convinced of the relevance and necessity of transforming all curricula in the education system into competency bases, since they believe that this is one of the best known approaches to meet the demands and challenges of society, both at the economic and social levels.

Over the past few decades, a more or less radical rewriting of the programs in Quebec and Belgium has taken place. In France, it was around 2000 that competencies appeared in the programs with the reform associated with the Common-Competency Base (Common 
base of competences). In French-speaking Switzerland, the issue is beginning to be debated, often conceived in terms of competences [1].

Pedagogical instructions and ministerial circulars on physical science teaching in Morocco specify teaching methods and set the total amount of time allocated to each module, each module element and each paragraph of the curriculum. This is done with a view to unifying the assessment for each grade level. Thus, the teacher is expected to teach and evaluate in the time allotted. On the other hand, the hourly volume given for the disciplinary field "physics and chemistry" (each module, module element and each paragraph) is not compatible with their content, posing thereby problems for teachers, especially for new recruits. In addition, the Official Instructions represent only a formal framework and do not allow to report on the real practices of the teachers with their students in class [2].

This work is part of a systematic study of the obstacles observed in learners, at secondary and university levels, concerning the chemistry module. Recent research has been undertaken on the difficulties encountered in Moroccan high school students, in terms of modeling a reaction $[3,4]$ and the lack of distinction between temperature and heat of future teachers $[5,6]$.

In the course of our study, we focused on the development of a simplified model of the different stages of the competency-based approach, adaptable to Moroccan pedagogical instructions, in order to ensure the performance of professional practices within teaching organizations and the management of time allocated to the curriculum, particularly for newly recruited teachers, and to achieve the targeted objectives.

This study aims to see how the modeling of the proposed "competency-based approach," as a teaching approach facilitates the professional practices of newly recruited teachers by helping them to comply with the guidelines of the teaching instructions. The approach aims also at developing the learners' communication skills, critical thinking skills, and self-confidence. This stipulates the exploration of a number of questions:

- $\quad$ Does the CBA method play a role in developing the learner's communication skills, self-confidence and scientific thinking in addition to the main characteristic of the CBA method which is the learner's contribution to the construction of the lesson?

- $\quad$ Does the adoption of the CBA method as a learning method by the Moroccan educational system have repercussions on its organizational and functional system?

- To what extent does the modelling of the CBA method according to the standards granted by the pedagogical instructions contribute to the achievement of the defined objectives, and facilitate the professional practice of newly recruited teachers?

This article consists of two parts:
- $\quad$ The first part concerns the study regarding the extent to which the CBA method contributes to the development of communication skills, scientific reflection and self-confidence.

- $\quad$ The second part of the study concerns the opinions of new teachers on the feasibility of using this modelling.

\section{The Research Process}

\subsection{The Survey Sample and Data Collection through Questionnaires}

The research was carried out at the Regional Centre for the Professions of Education and Training (CRMEF) in Casablanca-Settat, while the data was collected during the recruitment years in December 2016/2017, 2017/2018 and $2018 / 2019$. There were fifty-six teacher trainees recruited in the December 2016/2017 session (G1), fifty-six in the December 2017/2018 session (G2) and fifty recruited in the December 2018/2019 session (G3), resulting in a total of one hundred and sixty-two recruits, divided into two class groups for each year. It should be noted that the three data collection points are independent of each other and that the same recruits did not take part in all three data collections. Thus, the sample consists of twenty-eight recruits in 2016/207, twenty-eight recruits in 2017/2018 and twenty-five recruits in 2018/2019.

\subsection{Methodology}

In the course of this study, and in order to answer the questions posed at the outset, we thought it useful to use the following "wild teaching" methodology to identify the skills previously acquired by newly recruited teachers and how these skills developed after six months of training:

Each new recruit chooses the topic, from the chemistry module, that suits them and which they have already seen during their undergraduate preparation. Prior to the interview, a 15-minute preparation time is designed for each candidate. During the interview, the candidate has the necessary pedagogical tools that he needs in the lesson.

The candidates in question will have to expose, explain, express themselves and transmit freely the content of the chosen theme in their own way in a duration of $60 \mathrm{~min}$. A group of three teacher trainers (authors of the article) of chemistry and its didactics evaluate, based on a grid the following points:

- How the learning was transferred.

- Ability to convey the content of the chosen theme.

- Ability to exchange with others via the chosen theme.

- $\quad$ The level of confrontation with the other candidates.

- $\quad$ Respect for the time allowed.

After a six-month training course, based on the CBA method, the same group of trainers took the same approach for each candidate. The result thus found for each candidate is given in Table 1. 
Table 1. Result of the interview: Start of training at the CRMEF

(VS: Very satisfactory; QS: Quite satisfactory; SU: Somewhat unsatisfactory; NS: Not at all satisfactory)

\begin{tabular}{|c|c|c|c|c|c|c|c|c|c|c|}
\hline \multirow{2}{*}{ Competence sought } & \multirow{2}{*}{ Indicators } & \multirow{2}{*}{ Group } & \multicolumn{4}{|c|}{ Before training } & \multicolumn{4}{|c|}{ After training } \\
\hline & & & VS & QS & SU & NS & VS & QS & SU & NS \\
\hline \multirow{4}{*}{ Autonomy } & \multirow{4}{*}{$\begin{array}{l}\text { - The use of the available didactic tools } \\
\text { is done automatically. } \\
\text { Streamlined monitoring of the use of } \\
\text { scientific knowledge }\end{array}$} & 2016 - 2017 & $36 \%$ & $18 \%$ & $21 \%$ & $25 \%$ & $40 \%$ & $20 \%$ & $17 \%$ & $23 \%$ \\
\hline & & $2017-2018$ & $18 \%$ & $11 \%$ & $14 \%$ & $57 \%$ & $27 \%$ & $23 \%$ & $20 \%$ & $30 \%$ \\
\hline & & 2018 - 2019 & $12 \%$ & $8 \%$ & $8 \%$ & $72 \%$ & $22 \%$ & $28 \%$ & $17 \%$ & $33 \%$ \\
\hline & & Overall percentage & \multicolumn{2}{|c|}{$34 \%$} & \multicolumn{2}{|c|}{$66 \%$} & \multicolumn{2}{|c|}{$53 \%$} & \multicolumn{2}{|c|}{$47 \%$} \\
\hline \multirow{4}{*}{ Communication } & \multirow{4}{*}{$\begin{array}{l}\text { - Communication is linguistically } \\
\text { sound and helps to achieve the desired } \\
\text { goal. } \\
\text { - Correct and effective method of } \\
\text { communication }\end{array}$} & 2016 - 2017 & $14 \%$ & $18 \%$ & $25 \%$ & $43 \%$ & $20 \%$ & $25 \%$ & $25 \%$ & $43 \%$ \\
\hline & & $2017-2018$ & $11 \%$ & $7 \%$ & $29 \%$ & $54 \%$ & $25 \%$ & $31 \%$ & $22 \%$ & $22 \%$ \\
\hline & & 2018 - 2019 & $13 \%$ & $6 \%$ & $20 \%$ & $61 \%$ & $28 \%$ & $35 \%$ & $27 \%$ & $10 \%$ \\
\hline & & Overall percentage & \multicolumn{2}{|c|}{$23 \%$} & \multicolumn{2}{|c|}{$77 \%$} & \multicolumn{2}{|c|}{$55 \%$} & \multicolumn{2}{|c|}{$45 \%$} \\
\hline \multirow{4}{*}{ Self-confidence } & \multirow{4}{*}{$\begin{array}{l}\text { Reflection, precision and persuasion } \\
\text { in the face of others' questions. } \\
\text { - Convincing answers }\end{array}$} & 2016 - 2017 & $17 \%$ & $13 \%$ & $17 \%$ & $53 \%$ & $24 \%$ & $36 \%$ & $25 \%$ & $15 \%$ \\
\hline & & 2017 - 2018 & $15 \%$ & $12 \%$ & $15 \%$ & $56 \%$ & $30 \%$ & $34 \%$ & $26 \%$ & $20 \%$ \\
\hline & & $2018-2019$ & $13 \%$ & $9 \%$ & $13 \%$ & $65 \%$ & $28 \%$ & $38 \%$ & $24 \%$ & $10 \%$ \\
\hline & & Overall percentage & \multicolumn{2}{|c|}{$26 \%$} & \multicolumn{2}{|c|}{$74 \%$} & \multicolumn{2}{|c|}{$63 \%$} & \multicolumn{2}{|c|}{$37 \%$} \\
\hline
\end{tabular}


In the subsequent phase, we will work to closely identify the extent of the effectiveness of this modelling and its applicability, and whether it is possible for the teacher to respect the time coverage allocated for each unit of the program as indicated in the pedagogical guidelines, and whether the teacher can, by applying this modelling, achieve the aligned objectives. To this end, we adopted a questionnaire to solicit the opinions of new teachers regarding the applicability of this model and its facilitation of the teacher's work. This second part of the study was carried out after the end of the training period at the training center, and exactly three months after they had assumed full responsibility for the class.

\section{Outcome and Discussion}

\subsection{Before Training at the CRMEF: Phase of Detection, Identification and Evaluation of Professional Skills Acquired at the End of University Studies}

In this first part, we conducted a purely experimental study concerning the identification of skills and their mastery by new recruits in the Physical Science option at the CRMEF.
The current study consists, on the one hand, of exploring and identifying the percentages of skills already acquired by new recruits during their university career and, on the other hand, of evaluating and measuring the degree of mastery of these skills by the latter. In this context, we have focused on those that we feel are useful in this study, namely communication skills, self-confidence and confrontational skills. This study was carried out before the beginning of the training for each year of training and involved three groups, the 2016/2017 group (G1); the 2017/2018 group (G2) and the 2018/2019 group (G3), over a period of three consecutive years.

During this phase of the research, it was found that most future pre-service teachers suffer from a shortage of the skills studied and that this deficiency is exacerbated from year to year. Some of whom have a good command of these skills but lack the pedagogical and didactic qualifications.

Table 1 shows the percentages thus found during our study and Figure 1, 2 and 3 show their variations.

The results achieved in this paragraph remain normal because training at universities depends in most cases on theoretical training, which does not provide sufficient time for practical work, and does not provide students with on-the-job training in the subjects taught in theory, with most of them not having benefited from the communication module either.

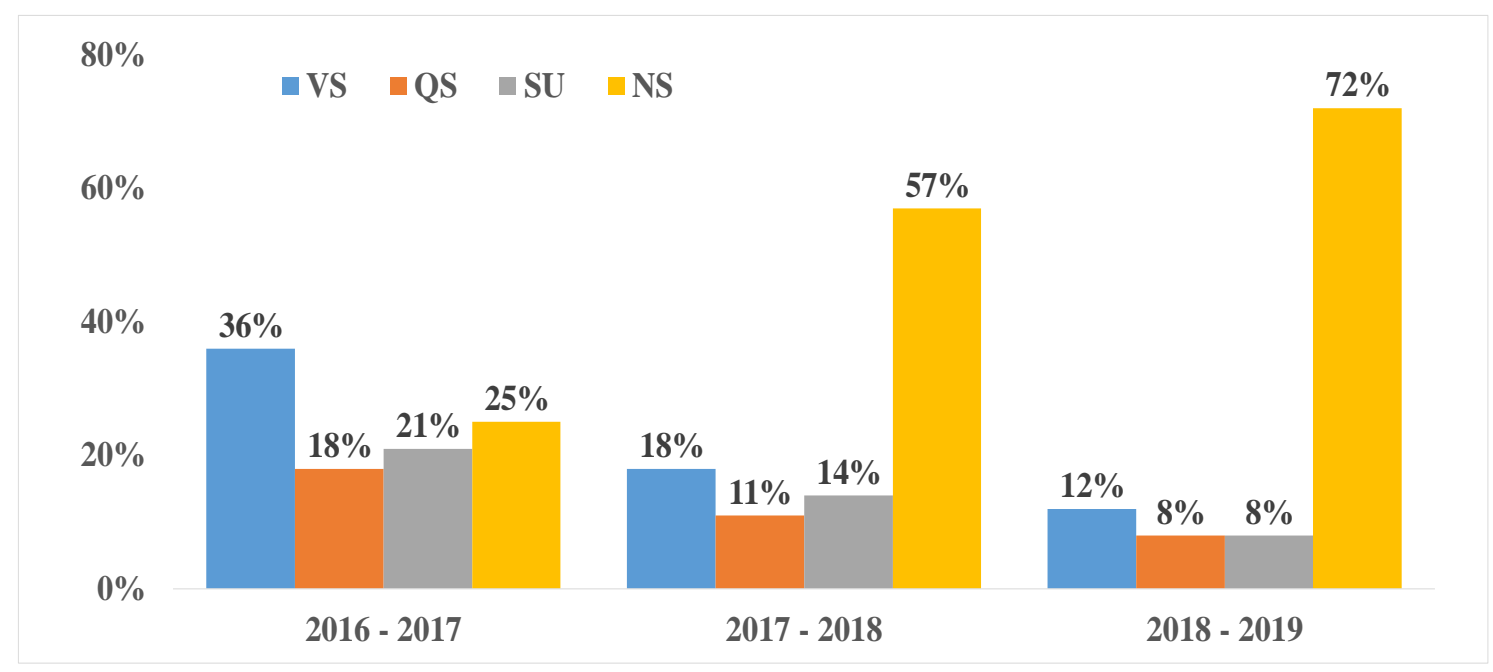

Figure 1. Representation of the Interview Result: Before training at CRMEF - Target Competency: Autonomy 


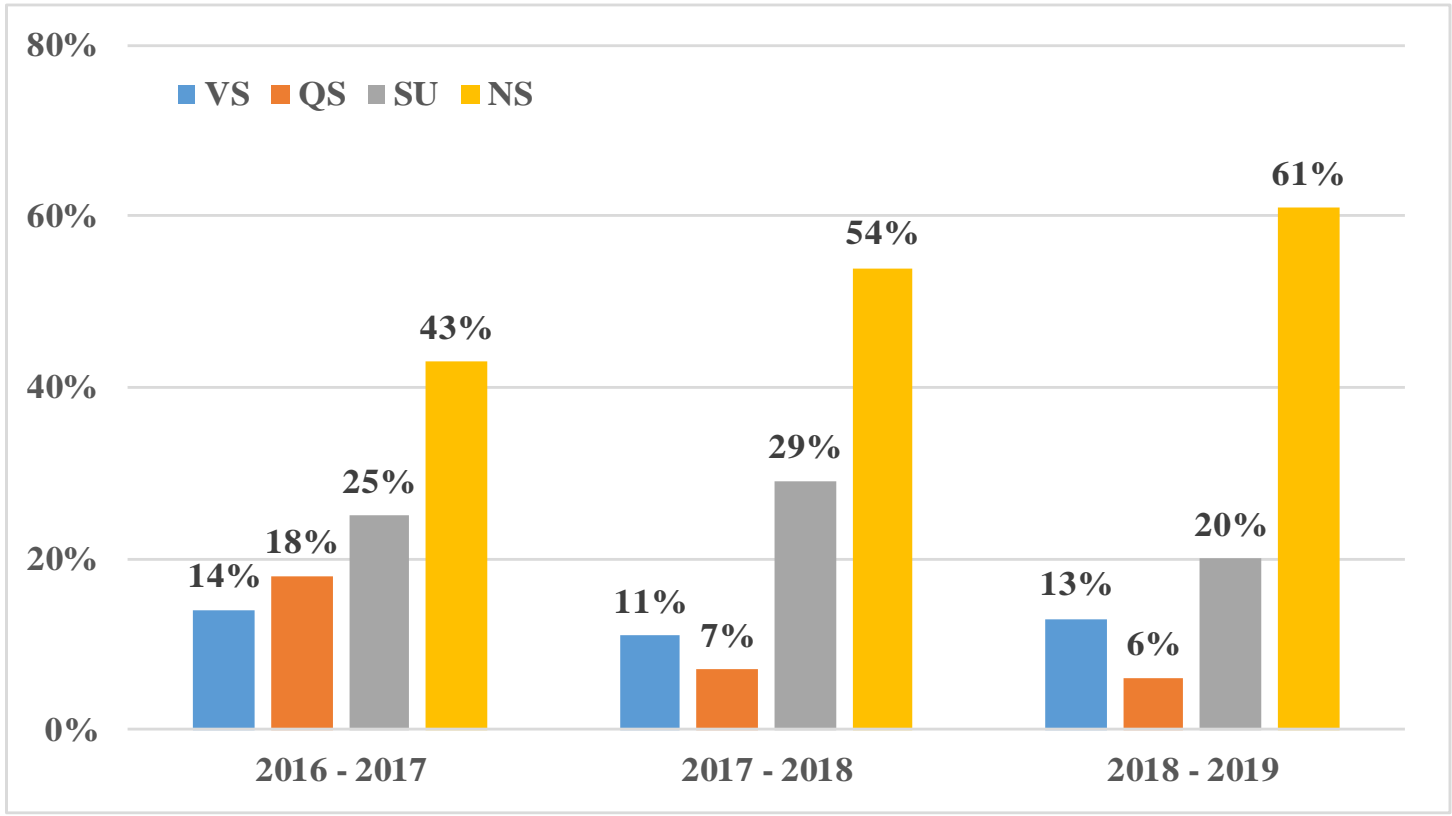

Figure 2. Representation of the Interview Result: Before training at CRMEF - Target Competency Communication

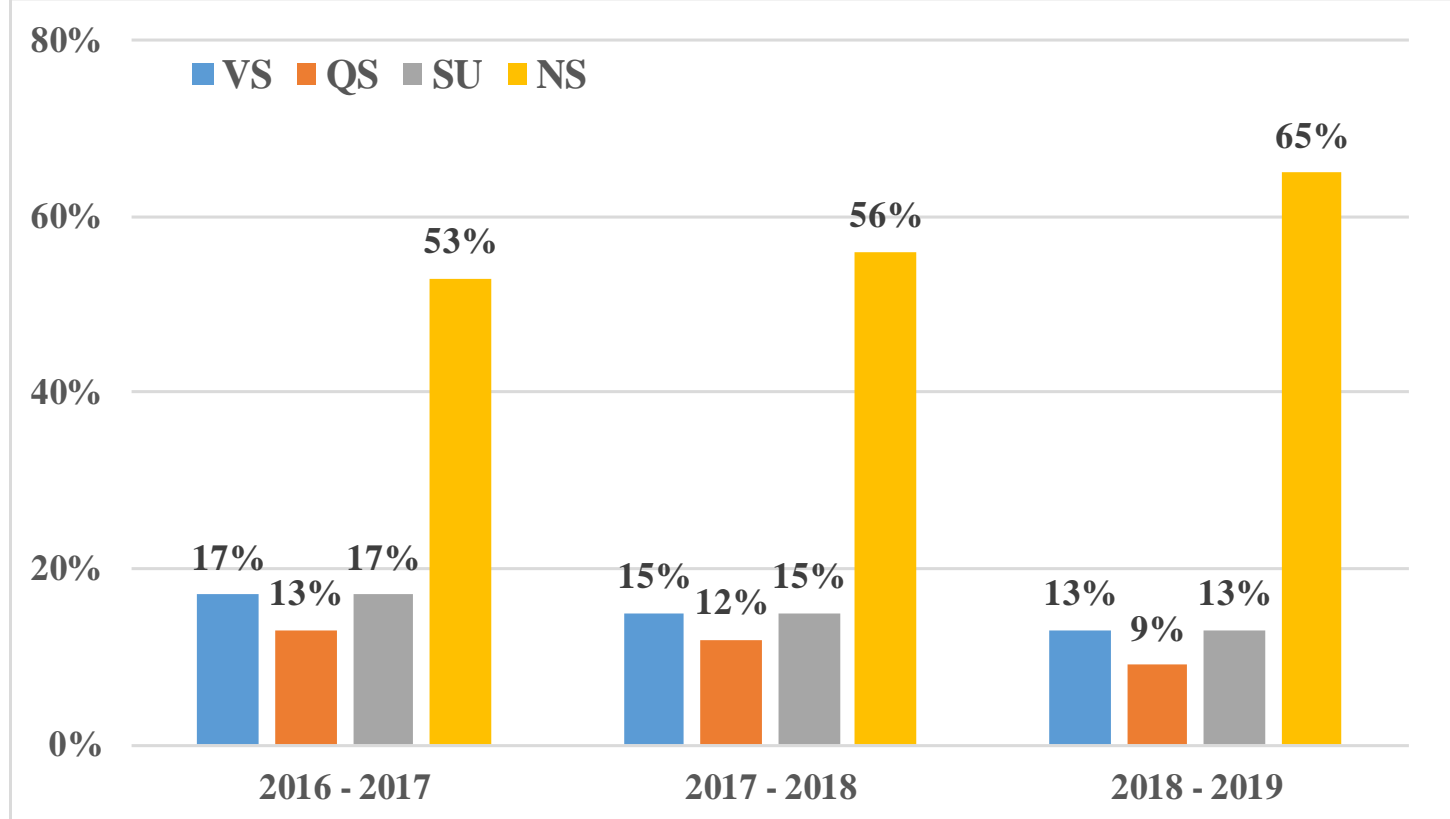

Figure 3. Representation of the Interview Result: Before training at CRMEF - Target Competency Self-confidence

3.2. After Training at the CRMEF: Remediation Phase, Regulation, Upgrading and Evaluation of Professional Skills

Building on the statistical data obtained by studying the skills identified in new recruits before the start of training using the 'wild teaching' methodology, we have focused on these skills during training by developing a training scheme appropriate to this objective, and by adopting the CBA learning method throughout the training period, due to its particular advantages $[7,8,9,10]$ in the abovementioned areas. Skills proficiency percentages were established for each of the recruits during the last week of training.

This study was carried out towards the end of the training for each year of training and involved three groups, group 2016/2017, group 2017/2018 and group 2018/2019, over a period of three consecutive years.

The post-training study, adopting the "competency-based approach" teaching approach, showed that the level of future teachers improved in the skills studied to a good extent (figure 4, 5 and 6). 


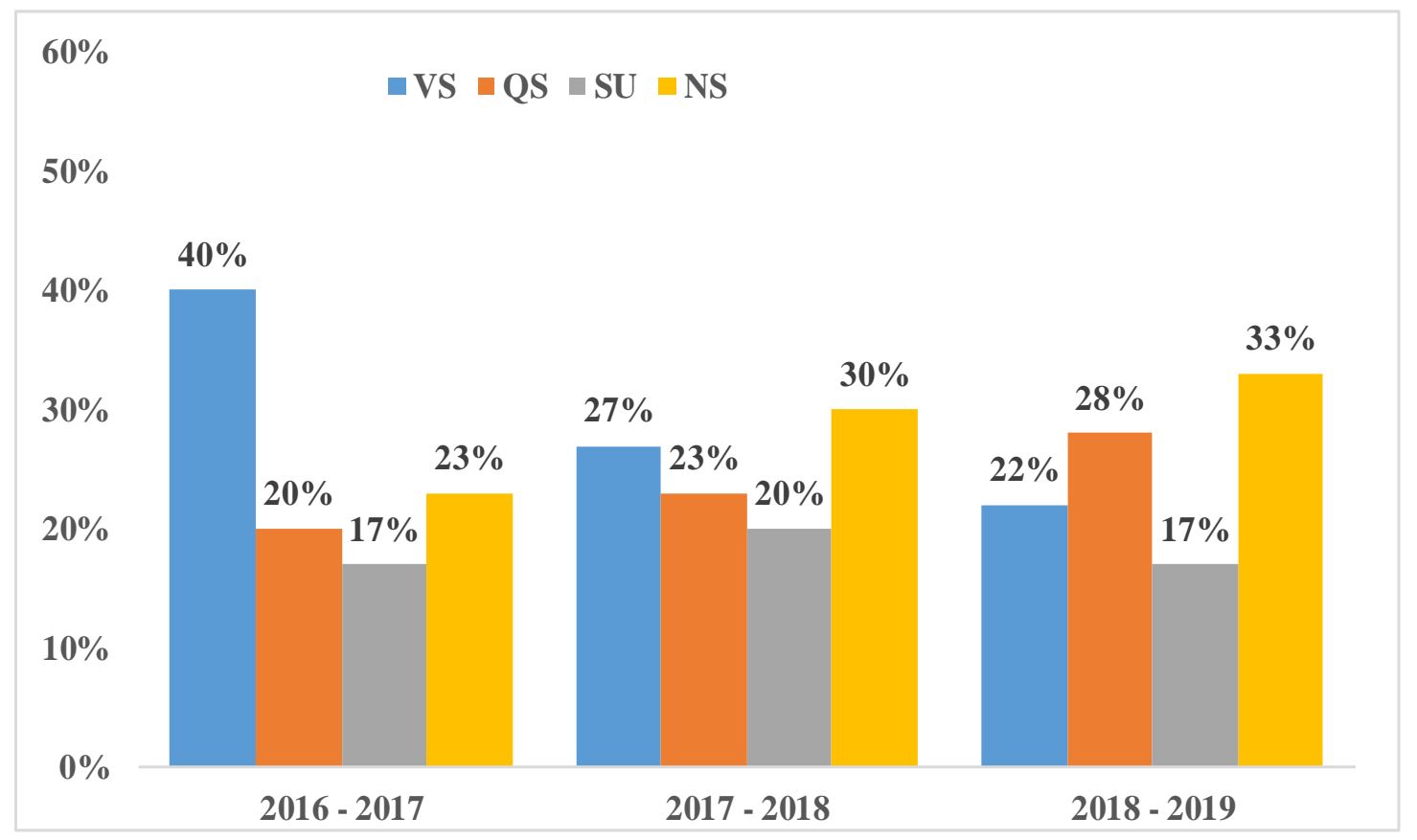

Figure 4. Representation of the Interview Result: End of training at CRMEF - Target Competency Autonomy

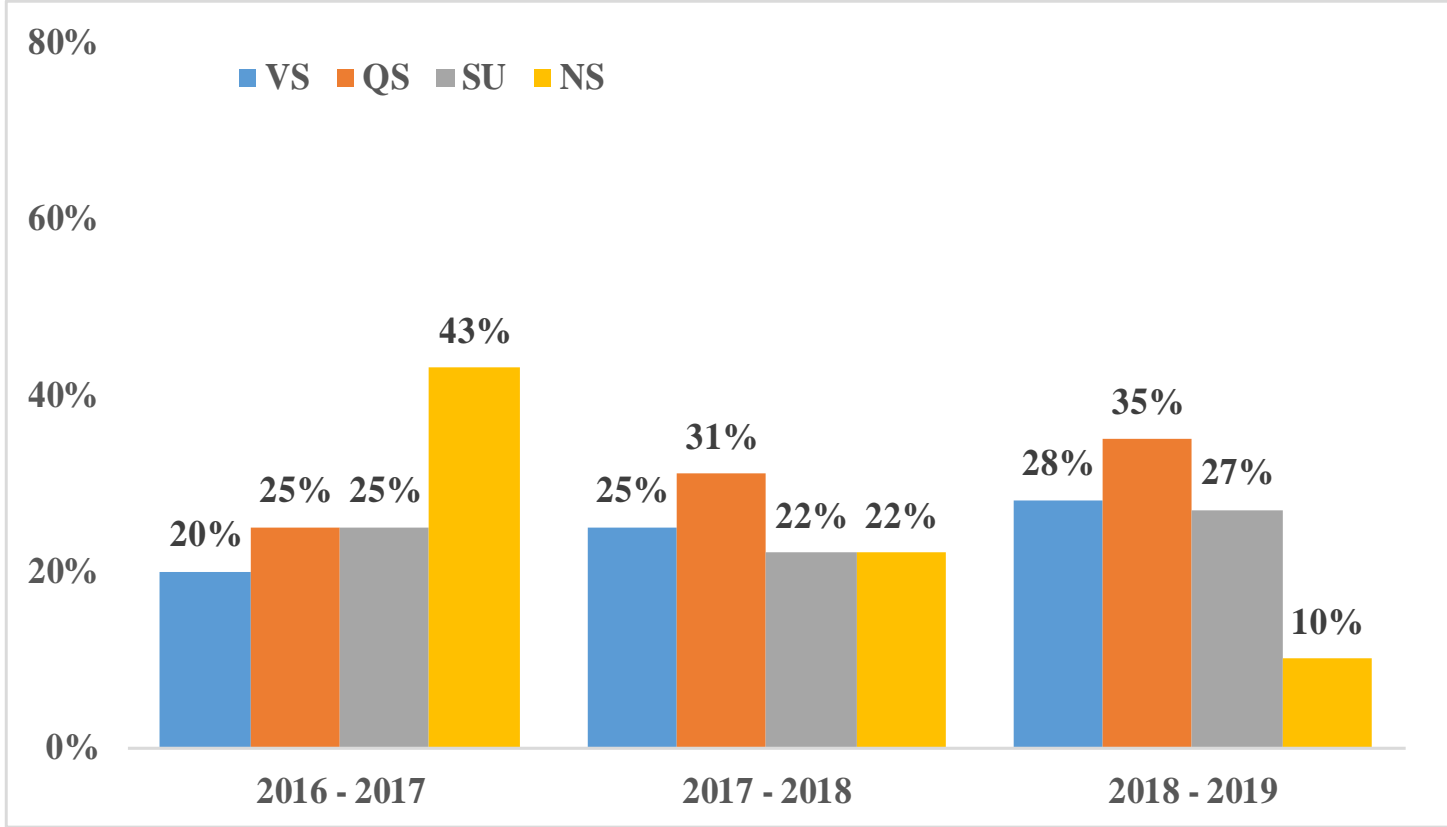

Figure 5. Representation of the Interview Result: End of training at CRMEF - Target Competency Communication 


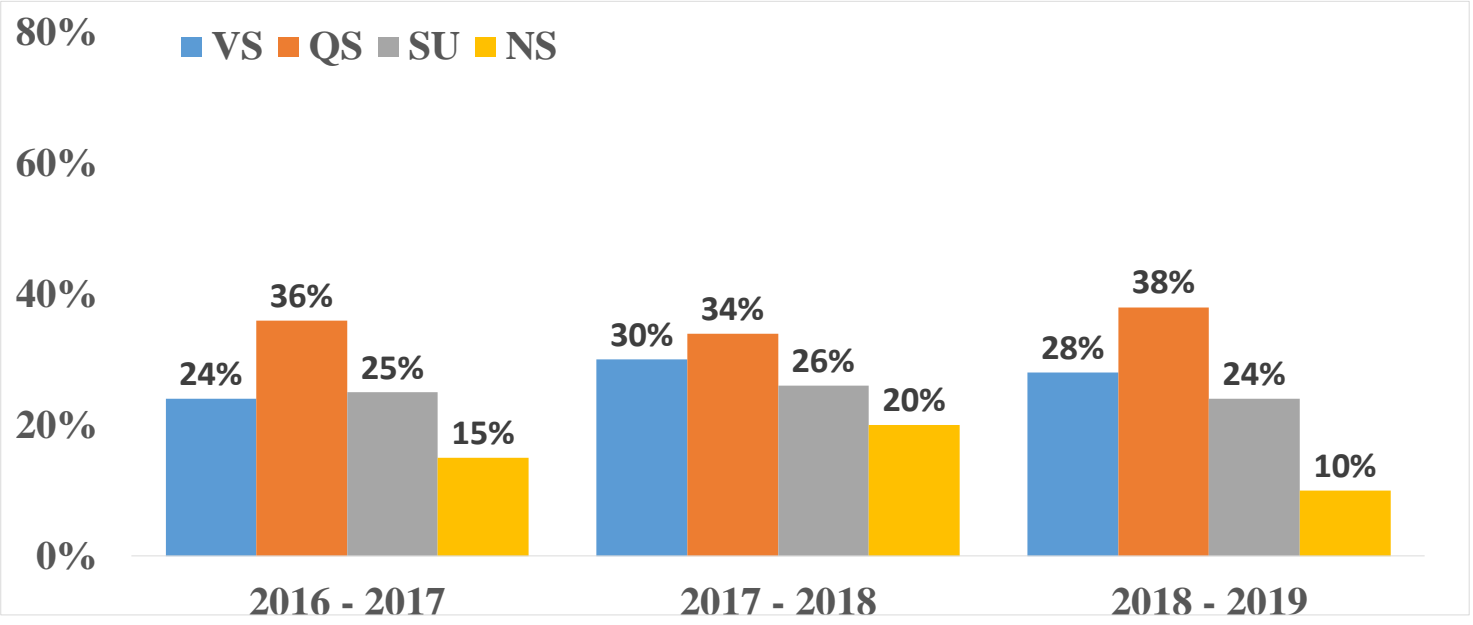

Figure 6. Representation of the Interview Result: End of training at CRMEF - Target Competency Self-confidence

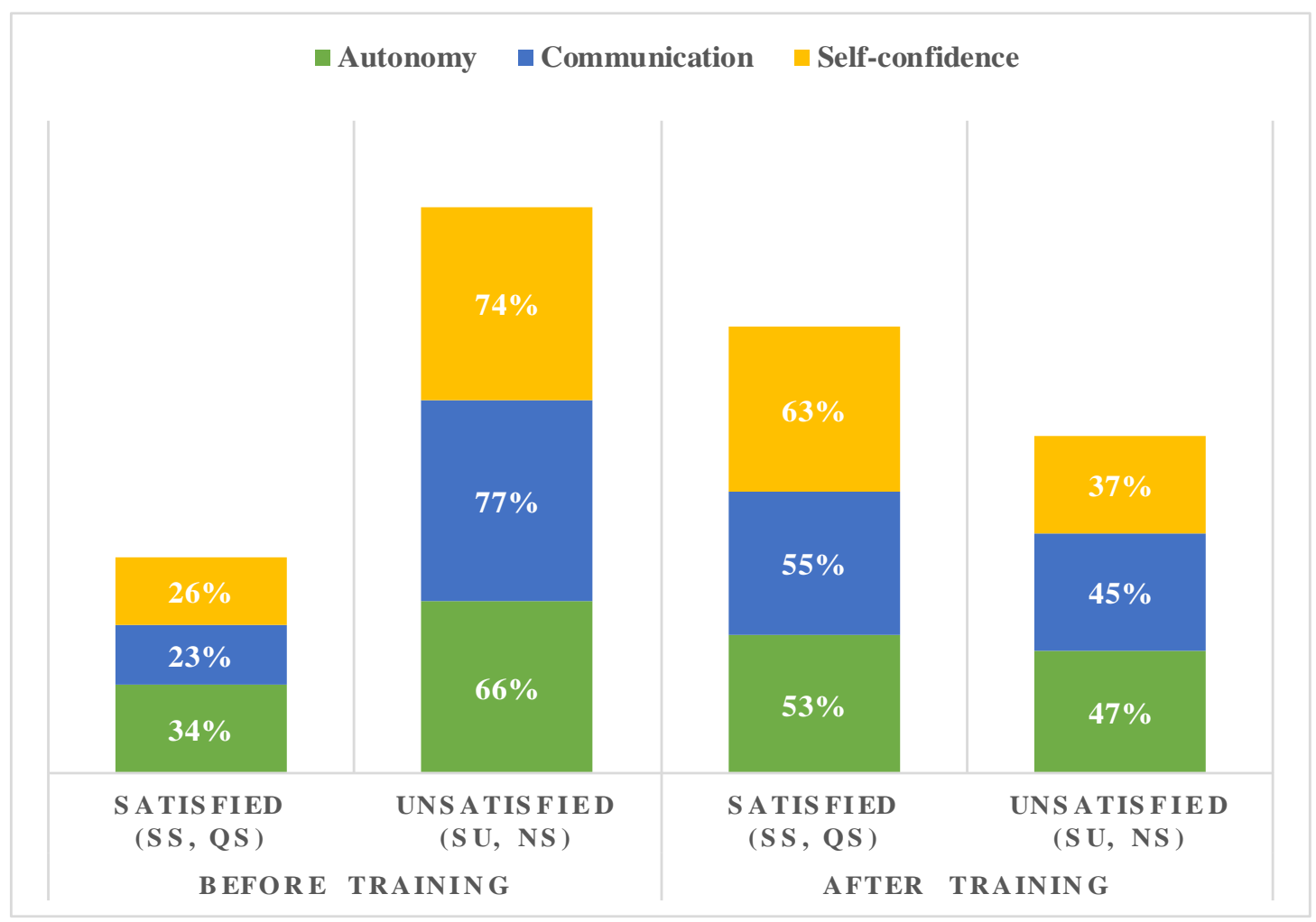

Figure 7. Representation of the evolution of the global satisfaction score of the three skills during the three years of study before and after training

In fact, the overall satisfaction gap (SS and QS), during the three years of study, between the beginning and the end of the training evolved by 19\% for the "autonomy" competence, $32 \%$ for the "communication" competence, and $37 \%$ for the "self-confidence" competence (Table 1; Figure 7).

Figure 7 shows that the overall satisfaction rate, calculated over the three years of the study, corresponding to each of these competencies is below average (34\%, 23\% and 26\%). On the other hand, the satisfaction rate for each competence evolves positively from the starting situation (beginning of training) to the end of training. We also found that the rate of evolution of each skill improves from one year to the next. This can be explained by the fact that the duration of training is significantly longer in 2018/2019 (seven months) compared to 2016/2017 (four months).

\subsection{Impact of Modeling on Teaching Practice}

Since modeling is at the heart of the scientific act, it is important to design a teacher training intervention that focuses on models and modelling. Moreover, recent 
research on modelling shows that knowledge about models and modelling of future teachers after the four- or five-years' degree remains rather weak and confusing (Danusso, Testa and Vicentini, 2010) [11]. In this context, it seems useful to model the different stages of the CBA teaching method in order to contribute to the improvement and perfection of the professional practice of new teachers. The following diagram (figure 9) summarizes the various stages of the proposed modeling. The latter has been the subject of an identification study on the attitudes of new teachers regarding the feasibility of using this modelling.

\subsection{What This Modeling Makes Possible}

The modeling proposed in this study is composed of four phases that are dependent on each other.

Phase 1: Formulation of the scientific problem: choice of a problem situation by the professor.

Phase 2: Appropriation of the problem by the students. During this phase, the learners take ownership of the problem to be solved which stems from the initial problem-situation while mobilizing their initial conceptions. The three moments proposed during this phase are:

- Confrontation, between groups or one-to-one, of their possible divergences to encourage the appropriation, by the class, of the problem to be solved;

- Individual reflection by the learners "what is the problem? "Individual reflection by the learners "What is the problem? "Reflect and write (questions, answers ....).

- $\quad$ Pooling (sharing opinions): Each student or group presents their suggestions with an explanation; the teacher writes the list on the board.

Phase 3: Verification of, the formulation of conjectures, hypotheses and possible protocols that have been adopted: During this phase, the learners are led to propose, in an "oral or written" way, conjectures, explanatory hypotheses and possible protocols that allow "testing these hypotheses or conjectures". The moments proposed during this phase are:

- $\quad$ Test the hypotheses from the institutions that are in relation with them or with reference persons,

- $\quad$ Test the hypotheses by experiment,

- Test hypotheses by observation,

- Test hypotheses with documents (written means, videos, ...).

Phase 4: Reinvestment: The objective of this phase is to automate the procedures followed during the session. It also allows to "master the forms of expression related to the knowledge worked on "linguistic or symbolic forms, graphic representations....”.

The operationalization of knowledge will be able to evaluate "knowledge and methodological skills" in students through their involvement in "new problems allowing the implementation of knowledge acquired in new contexts (reinvestment)". The moments proposed during this phase are: Pooling; Restructuring and Synthesis.

The modeling thus proposed was tested with three classes of new teachers in the training years 2016/2017 (G1), 2017/2018 (G2) and 2018/2019 (G3), when they were put in a professional situation during the first semester. In the course of this study, we asked new teachers to indicate, from their point of view, the contributions of such modelling, making a few proposals that were not mutually exclusive. The questions asked were as follows:

\section{Q1: Do you think that this modeling allows you (several answers possible):}

$\square$ To progress.

$\square$ To become aware of your evolution.

$\square$ To modify your methods.

$\square$ To be more motivated.

$\square$ To respect the time slot allotted for each paragraph of the course.

$\square$ Achieve the desired objective of the paragraph of the course you are studying.

\section{Q2: How did you find this model when you tried it out in class?}

$\square$ Proposition 1: practical and somewhat applicable.

$\square$ Proposition 2: not practicable but applicable.

$\square$ Proposition 3: practical and effectively applicable.

In general, the statistical study on the first question showed that a large part of the respondents (with an overall percentage of $75 \%$, table 2) agreed that modeling this method of teaching allowed them to acquire and improve a set of skills such as awareness of evolution, changing methods, being more motivated and progressing... while we register a variation from the last two proposals relating to "respecting the time slot allocated to each paragraph of the lesson" and "achieving the desired objective for each paragraph of the lesson.

Table 2. Counting of Responses to Question Q1

\begin{tabular}{|l|c|c|c|c|}
\hline \multirow{2}{*}{ Proposals related to question1 (Q1) } & \multicolumn{3}{|c|}{$\%$ Response rate } & \multirow{2}{*}{$\begin{array}{c}\% \\
\text { OPR }\end{array}$} \\
\cline { 2 - 4 } & $\mathrm{G}_{1}$ & $\mathrm{G}_{2}$ & $\mathrm{G}_{3}$ & \\
\hline$\square$ To progress. & 77 & 73 & 75 & \\
\hline $\begin{array}{l}\text { To become aware of your } \\
\text { evolution. }\end{array}$ & 69 & 74 & 82 & \multirow{2}{*}{75} \\
\hline$\square$ To modify your methods. & 71 & 67 & 87 & \\
\hline$\square$ To be more motivated. & 72 & 63 & 90 & \\
\hline $\begin{array}{l}\text { To respect the time slot allocated } \\
\text { for each paragraph of the course. }\end{array}$ & 47 & 50 & 38 & \multirow{2}{*}{45} \\
\hline $\begin{array}{l}\square \text { Achieve the desired objective of } \\
\text { the paragraph of the course you are } \\
\text { studying. }\end{array}$ & 89 & 74 & 85 & \multirow{2}{*}{85} \\
\hline
\end{tabular}

* Overall Percentage of Responses 


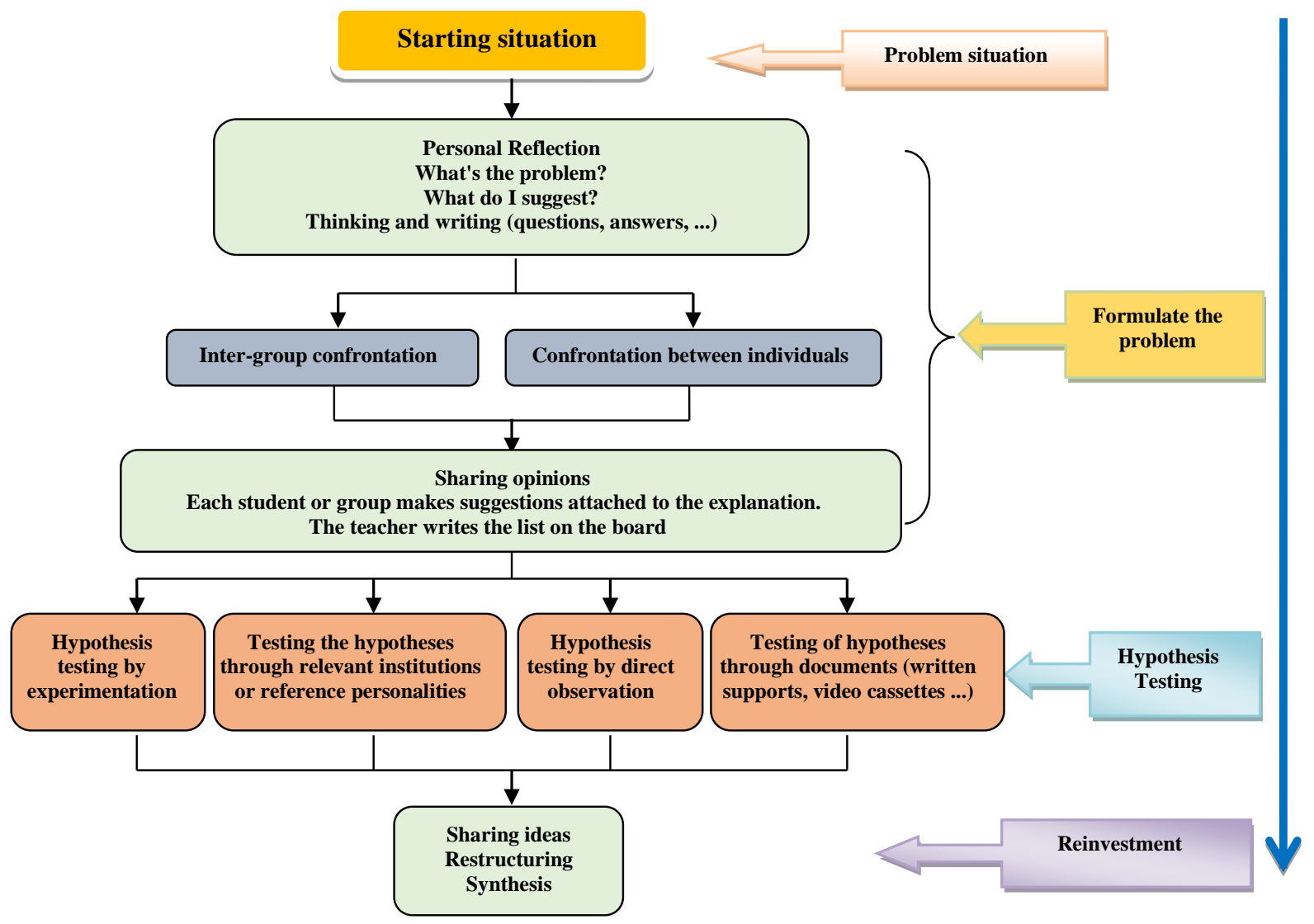

Figure 9. Modelling of the different stages of the CBA method

Regarding the proposal "respect of the time slot allocated to each paragraph of the lesson" an overall percentage of $(45 \%$, table 2$)$ of the teachers interviewed replied that the amount of time allocated to each paragraph is related to the nature of the concepts mentioned in each paragraph, the number of learners in the class, and the abundance or unavailability of the didactic tools for the lesson .... For the proposal "the achievement of the desired objective for each paragraph of the lesson", $85 \%$ of the respondents judged that: This modeling (figure 9) often allows them to achieve the underlined objective of each paragraph of the lesson regardless of the time space allowed for that paragraph.

Regarding the survey of teachers on the feasibility of this modeling from the point of view of application and practice $(\mathrm{Q} 2)$, the statistical data collection of this survey is indicated in the table 3 , figure 10 .

Respondent results (table 3, figure 10) regarding the application and practice of the proposed modeling in the field of learning show that an overall percentage of respondents $55 \%$ felt that it is practical and effectively applicable, and $25 \%$ responded that it is practical and somewhat applicable; $8 \%$ stated that it is rather not practicable but applicable. From the statistical study, it can be deduced that $100 \%$ of the teachers confirmed the effectiveness of the modeling in terms of application while $8 \%$ of them only agreed on its effectiveness in terms of practice.

Table 3. Percentage (\%) of responses from each training group (Gi) to the three items (Qi)

\begin{tabular}{|c|c|c|c|c|c|}
\hline Theme & Item & $\begin{array}{l}\mathrm{G}_{1} \\
\%\end{array}$ & $\begin{array}{l}\mathrm{G}_{2} \\
\% \\
\end{array}$ & $\begin{array}{l}\mathrm{G}_{3} \\
\%\end{array}$ & $\begin{array}{c}\text { medium } \\
\text { percentage }\end{array}$ \\
\hline \multirow{3}{*}{$\begin{array}{l}\text { How did you find this } \\
\text { model when you tried } \\
\text { it out in class? }\end{array}$} & \multirow{3}{*}{$\begin{array}{l}\mathrm{P}_{1} \\
\mathrm{P}_{2} \\
\mathrm{P}_{3}\end{array}$} & 30 & 25 & 21 & $25 \%$ \\
\hline & & 05 & 08 & 12 & $8 \%$ \\
\hline & & 65 & 57 & 47 & $55 \%$ \\
\hline
\end{tabular}




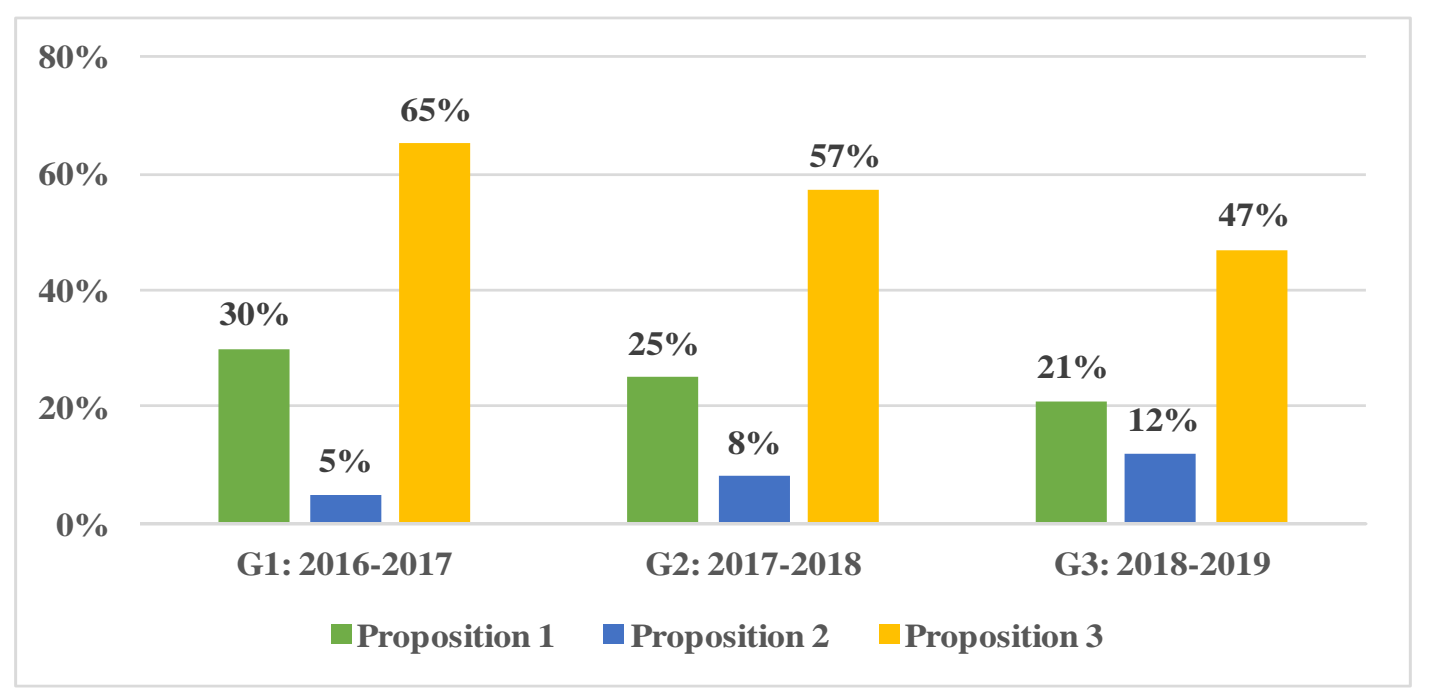

Figure 10. Percentage (\%) of responses from each training group (Gi) to the three items (Qi).

\section{Conclusions}

The most important findings that can be drawn from this study are that academic teaching in universities remains insufficient to qualify students for the teaching profession and that the role of training centers remains pivotal and essential, particularly in the fields of pedagogy, didactics, analysis of professional practices and didactic production. The sharp decline in the level of university graduates from year to year in basic subjects in terms of physics and chemistry can also be noted.

On the other hand, teaching methods and modelling are among the main pillars of the teaching profession. Indeed, from this study, it can be stated that the "competency-based approach" allows the learner to acquire many skills, including communication, self-confidence, and allows the development of scientific thinking for the learner. From this study, it can be judged that modelling can contribute to the improvement and perfection of the professional practice of new teachers.

\section{REFERENCES}

[1] Perrenoud, P., Construire des compétences, est se tourner le dos aux savoirs ? Faculté de psychologie et des sciences de l'éducation, Université de Genève, In Résonances, Mensuel de l'école valaisanne, $\mathrm{n}^{\circ} 3$, Dossier «savoirs et compétences», p. 1 (1998).

[2] Sandra, F. L'enseignement de l'écrit dans les programmes ministériels de l'école primaire, Actes du congrès de l'Actualité de la recherche en éducation et en formation (AREF), Université de Genève, septembre 2010.

[3] I. ElKababi, A. Atibi, M. Radid, S. Belaaouad, S. Tayane, Assessment of Learners' learning about Temperature and
Heat concepts, International Journal of Advanced Trends in Computer Science and Engineering, 9(2), March - April 2020, 956 - 962

[4] El Kababi, K., A. Atibi, M. Radid, and A. Benmassaoud. "Difficulties Encountered by the Moroccan High School Students at the Level of the Modelling and the Course of a Chemical Reaction”. New Trends and Issues Proceedings on Humanities and Social Sciences, Vol. 3, no. 1, June 2017, pp. 95-05,

[5] C. Srour, A. Atibi, K. Elkababi, M. Radid, Evaluation of learning and its practices in high school through the reforms of the Moroccan education system, Test Engineering and Management, Volume 83, Page Number: 8654-8664, Publication Issue: March-April 2020

[6] Atibi, A., Kababi, K. E., Kababi, I. E., Radid, M., Talbi, M. (2017). Difficulties encountered by Moroccan Student in Studying Oxydoreduction. IJIRES Volume 4, Issue 1, ISSN (Online) : 2349-5219

[7] Rabii, H. Éducation, croissance économique et développement Humain : Le Cas Du Maroc. Mémoire (Inédit). Québec : Université de Québec à Montréal (2011).

[8] Scallon, G.. L'évaluation des apprentissages dans une approche par compétences. Saint-Laurent: Éditions du Renouveau pédagogique (2007).

[9] Adiza, H. «Les réformes curriculaires en Afrique francophone: investissements et résultats, quel paradoxe ?». Dans Daviau, C., Cyr, S., Charland, P., et Simbangoye, A. (2012). Écoles en mouvements et réformes. Enjeux défis et perspectives. Bruxelles: De Boeck supérieur (2012)..

[10] Beckers, J. (2012). Apprendre par compétences et réduction des inégalités d'apprentissages entre élèves : de l'analyse des situations scolaires à la formation des enseignants. Bruxelles: De Boeck.

[11] Danusso, L., Testa, I. \& Vicentini, M., 2010. «Improving Prospective Teachers' Knowledge about Scientific Models and Modelling: Design and evaluation of a teacher education intervention». International Journal of Science Education, $\mathrm{n}^{\circ}$ 32, vol. 7, p. 871-905 